\title{
Nucleotide sequences of the Bacillus subtilis flaD locus and a B. licheniformis homologue affecting the autolysin level and flagellation
}

\author{
J. Sekiguchi, ${ }^{1 *}$ H. Ohsu,${ }^{1}$ A. Kuroda,${ }^{1}$ H. Moriyama ${ }^{2}$ and T. Akamatsu ${ }^{2}$ \\ ${ }^{1}$ Department of Applied Biology, Faculty of Textile Science and Technology, Shinshu University, 3-15-1 Tokida, \\ Ueda-shi, Nagano 386, Japan \\ ${ }^{2}$ Department of Applied Microbiology and Technology, Kumamoto Institute of Technology, Ikeda 4-22-1, \\ Kumamoto 860, Japan
}

(Received 20 December 1989; revised 5 March 1990; accepted 12 March 1990)

\begin{abstract}
A DNA fragment containing the flaD locus of Bacillus subtilis, which had been cloned into plasmid pAC3, was subcloned into an M13 phage and sequenced. The sequence contained five open reading frames (ORFs), of which ORF2 was the $f l a D$ gene. Unexpectedly, the sequence of the $f a D$ locus was identical to that of sin [sporulation inhibition gene; Gaur, N. K., Dubnau, E. \& Smith, I. (1986). Journal of Bacteriology 168, 860-869]. A B. licheniformis homologue ( $f(a L)$ of the $B$. subtilis flaD locus was cloned into pUC19 and identified by colony hybridization. The B. licheniformis DNA was subcloned and sequenced. Two ORFs (ORF1, or L-ORF1; and ORF2, or $f l a L$ ) were detected, encoding 58 and 111 amino acid residues, respectively. These are almost identical in length to ORF1 (D-ORF1; 57 amino acids) and $f a D$ (111 amino acids) on the fragment of $B$. subtilis DNA. The overall interspecies differences between the nucleotide sequences of D-ORF1 and L-ORF1, and those of flaD and flaL, were $42 \%$ and $11 \%$, respectively, and the differences in the predicted amino acid sequences were $50 \%$ and $7 \%$, respectively. The regions $3^{\prime}$ of the ORFs ( $f l a L$ and $f l a D$ ) in both species resemble rho-independent terminators of transcription. The characteristics of the amino acid sequences are also discussed.
\end{abstract}

\section{Introduction}

In Bacillus subtilis, autolysin(s) affect cell separation (Fein \& Rogers, 1976), helical growth (Mendelson, 1982), flagellation (motility) (Fein, 1979) and competence (Ayusawa et al., 1975; Akamatsu \& Sekiguchi, $1987 \mathrm{~b}$ ), in addition to cell lysis. Since autolysins are important in cell morphology and physiology, autolysindeficient mutants of $B$. subtilis have often been isolated, but no previous papers have indicated whether the mutations are in the structural genes of autolysins or in genes affecting their expression. One class of autolysindeficient mutations, containing $l y t-1$ and $l y t-2$ (Fein \& Rogers, 1976), was found to be localized in the flaD locus (Pooley \& Karamata, 1984; Akamatsu \& Sekiguchi, $1987 a, b)$. Mutations at this locus led to decreases in the activities of two major autolytic enzymes $(N$-acetylmuramoyl-L-alanine amidase and endo- $\beta$ - $N$-acetylglucosaminidase). Recently, we cloned a $2.8 \mathrm{~kb}$ Pst I fragment

Abbreviation: ORF, open reading frame.

The nucleotide sequence data reported in this paper have been submitted to GenBank and have been assigned the accession number M31123. from the chromosome of $B$. subtilis $168 \mathrm{~W}$ which suppresses the $\mathrm{FlaD}^{-}$phenotype (Sekiguchi et al., 1988). An internal $1.0 \mathrm{~kb} \mathrm{XbaI-HindIII} \mathrm{fragment} \mathrm{also} \mathrm{sup-}$ pressed the $\mathrm{FlaD}^{-}$phenotype, and recombination analysis indicated that the cloned fragments contained the flaD gene itself (Sekiguchi et al., 1988).

In this communication, we report the nucleotide sequence of $f a D$ and show it to be identical to $\sin$, a previously reported gene responsible for inhibition of sporulation (Gaur et al., 1986, 1988). We also describe the cloning and sequence analysis of a $B$. licheniformis homologue of the flaD locus.

\section{Methods}

Bacterial strains and plasmids. These are listed in Table 1. Plasmid pAC32R was constructed by blunt-ending an EcoRI-EcoRV fragment containing the kanamycin-resistance gene $\left(\mathrm{Km}^{\mathrm{r}}\right)$ of $\mathrm{pAC} 3$ and a $B$. subtilis ori locus, and cloning into the blunt-ended EcoO109 site of pUC19. Thus, pAC32R acted as a shuttle vector between $B$. subtilis and Escherichia coli, expressing $\mathrm{Km}^{\mathrm{r}}$ in both species and $\mathrm{Lac}^{+}$and ampicillin resistance $\left(\mathrm{Ap}^{\mathrm{r}}\right)$ in $E$. coli.

Media. L broth, containing, per litre, $10 \mathrm{~g}$ polypeptone (Wako Pure Chemicals), $5 \mathrm{~g}$ yeast extract (Difco), $1 \mathrm{~g}$ glucose and $5 \mathrm{~g} \mathrm{NaCl}(\mathrm{pH}$ 
Table 1. Bacterial strains, phages and plasmids

\begin{tabular}{|c|c|c|}
\hline & Genotype & Source* or reference \\
\hline \multicolumn{3}{|l|}{ Bacillus subtilis } \\
\hline AG5 & purB6 arg-15 rgn-1 (flaD) leuB8 & Akamatsu \& Sekiguchi (1987a) \\
\hline AC 333 & purB lyt-2 (flaD2) & Akamatsu \& Sekiguchi (1987a) \\
\hline \multicolumn{3}{|l|}{ B. licheniformis } \\
\hline FD0120 & met-1 pepA & Akamatsu \& Sekiguchi (1984) \\
\hline \multicolumn{3}{|l|}{ Escherichia coli } \\
\hline JM109 & $\begin{array}{l}\text { recAl } \triangle(\text { lac-proAB }) \text { endAI gyrA96 thi-I } \\
\text { hsdR17 relA1 supE } 44\left[\mathrm{~F}^{\prime}: \text { traD36 pro } A B\right. \\
\left.\text { lacI } I^{9} \mathrm{Z} \Delta \mathrm{M} 15\right]\end{array}$ & Takara \\
\hline MV1184 & $\begin{array}{l}\text { ara } \Delta(\text { lac-pro }) \text { strA thi }(\phi 80 \text { lac } Z \Delta \mathrm{M} 15) \\
\Delta(\text { srl-recA }) 306:: \operatorname{Tn} 10\left(\text { tet }^{\mathrm{r}}\right) \\
{\left[\mathrm{F}^{\prime}: \text { traD36 proAB lacI }{ }^{\mathrm{q}} Z \Delta \mathrm{M} 15\right]}\end{array}$ & Takara \\
\hline \multicolumn{3}{|c|}{ 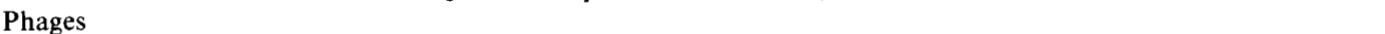 } \\
\hline M13mp18 and M13mp19 & & Yanisch-Perron et al. (1985) \\
\hline M13KO7 & & Takara \\
\hline \multicolumn{3}{|l|}{ Plasmids } \\
\hline $\mathrm{pAC} 3$ & $A p^{r} T c^{r} K m^{r}$ & Moriyama et al. (1988) \\
\hline pAC $32 R$ & $\begin{array}{l}\mathrm{Ap}^{r} \mathrm{Km}^{r} \mathrm{Lac}^{+} \text {in E. coli } \\
\mathrm{Km}^{r} \text { in } B . \text { subtilis }\end{array}$ & This study \\
\hline pBRG1 & $\mathrm{Tc}^{\mathrm{r}} \mathrm{Km}^{\mathrm{T}}$ & Sekiguchi et al. (1988) \\
\hline pUC19 & $\mathrm{Ap}^{\mathrm{r}} \mathrm{Lac}^{+}$ & Yanisch-Perron et al. (1985) \\
\hline $\mathrm{pUC} 118$ and $\mathrm{pUC} 119$ & $\mathrm{Ap}^{\mathrm{r}} \mathrm{Lac}^{+}$ & Takara \\
\hline
\end{tabular}

* Takara is a commercial supplier: Takara Shuzo Co., Kyoto, Japan.

7.2), was used for the growth of E. coli. Bacillus spp. were grown on nutrient broth, containing, per litre, $10 \mathrm{~g}$ beef extract (Difco), $10 \mathrm{~g}$ polypeptone and $2 \mathrm{~g} \mathrm{NaCl}(\mathrm{pH} \mathrm{7 \cdot 0)}$ ). Both media were solidified by the addition of $15 \mathrm{~g}$ agar. If necessary, kanamycin and ampicillin were added to final concentrations of $5 \mu \mathrm{g} \mathrm{ml}^{-1}$ and $50 \mu \mathrm{g} \mathrm{ml}^{-1}$, respectively.

For protoplast regeneration, HCP-1.5 medium (Akamatsu \& Sekiguchi, 1984) was used.

DNA manipulations. Standard cloning procedures (Maniatis et al., 1982) were used. Colony hybridization was also performed as described by Maniatis et al. (1982); plasmid pBRGl, used as a probe, was radiolabelled with a nick-translation kit (Nippon Gene).

$D N A$ sequencing. Nucleotide sequencing was done by the dideoxy chain-termination method with a modified T7 polymerase (Sequenase; Toyobo). Phages M13mp 18 and M13mp19 (Takara), or plasmids pUC118 and pUC119 (Takara) were used to generate templates for sequencing, and phage M13KO7 (Takara) was used as a helper phage. Electrophoresis was performed on $8 \%(\mathrm{w} / \mathrm{v})$ polyacrylamide $/ 8 \mathrm{M}$-urea gels.

A $1.05 \mathrm{~kb}$ HindlII fragment containing the $f a D$ gene of pUC12EX (Sekiguchi et al., 1988) was subcloned into the unique $H$ indIII site of pUC19 DNA. The resultant plasmid, pFLAD, was then digested with restriction enzymes, exonuclease III and mungbean nuclease to construct several deletion derivatives. The $B$. subtilis DNA fragments in these derivatives were subcloned into $\mathrm{M} 13 m p 19$ and sequenced using the strategy outlined in Fig. 1

Protoplast transformation of $B$. subtilis. This was done as described previously (Akamatsu \& Sekiguchi, 1984).

Measurement of autolytic activity. The autolytic enzymes, and cell walls for their assay, were prepared as described previously (Akamatsu \& Sekiguchi, 1983).

Observation of cell motility and morphology. Cell motility was investigated on nutrient agar containing $0.5 \%$ agar, by phase-contrast microscopy. Cell morphology was observed during exponential growth in nutrient broth.

\section{Results and Discussion}

Nucleotide sequence of the flaD gene

We have cloned a $2.8 \mathrm{~kb} P$ st $\mathrm{I}$ fragment of $B$. subtilis $168 \mathrm{~W}$ DNA carrying the $f a D$ gene, and the gene was found to be located between the HindIII and $X b a$ I sites (1.0 kb apart) (Sekiguchi et al., 1988). Surprisingly, the nucleotide sequence of the $1037 \mathrm{bp}$ fragment containing the $f l a D$ gene was identical to that containing the sin gene (sporulation inhibition phenotype; Gaur et al., 1986). The map position of $f a D$ on the $B$. subtilis chromosome was similar to that of $\sin$, and the $\mathrm{FlaD}^{-}$phenotype (filamentous, poor competence, and an increase in protease activity) was also similar to that of $\mathrm{Sin}^{-}$cells (Akamatsu \& Sekiguchi, 1983, 1987b; Gaur et al., 1986). These results indicate that the $f a D$ locus corresponds to the $\sin$ locus. Since there are five ORFs on the fragment (Fig. 1; Gaur et al., 1986), we subcloned the XbaIHindIII, XbaI-BalI, Sau3AI-DdeI, DdeI-HindIII, $X b a \mathrm{I}-D d e \mathrm{I}$ and Sau3AI-HindIII fragments into the corresponding sites of $\mathrm{pAC} 32 \mathrm{R}$, the cloned plasmids being designated as pFLAD0, pFLAD1, pFLAD2, pFLAD3, pFLAD 12 and pFLAD23, respectively (Fig. 1). Fragments containing ORF2, but none of the other ORFs, suppressed the FlaD ${ }^{-}$phenotype of $B$. subtilis AC333. Since the Sin function was located in ORF2 (Gaur et al., 1986), the flaD gene was identical to the $\sin$ gene.

Gaur et al. (1986) suggested that the Sin protein is a DNA-binding protein containing a helix-turn-helix 


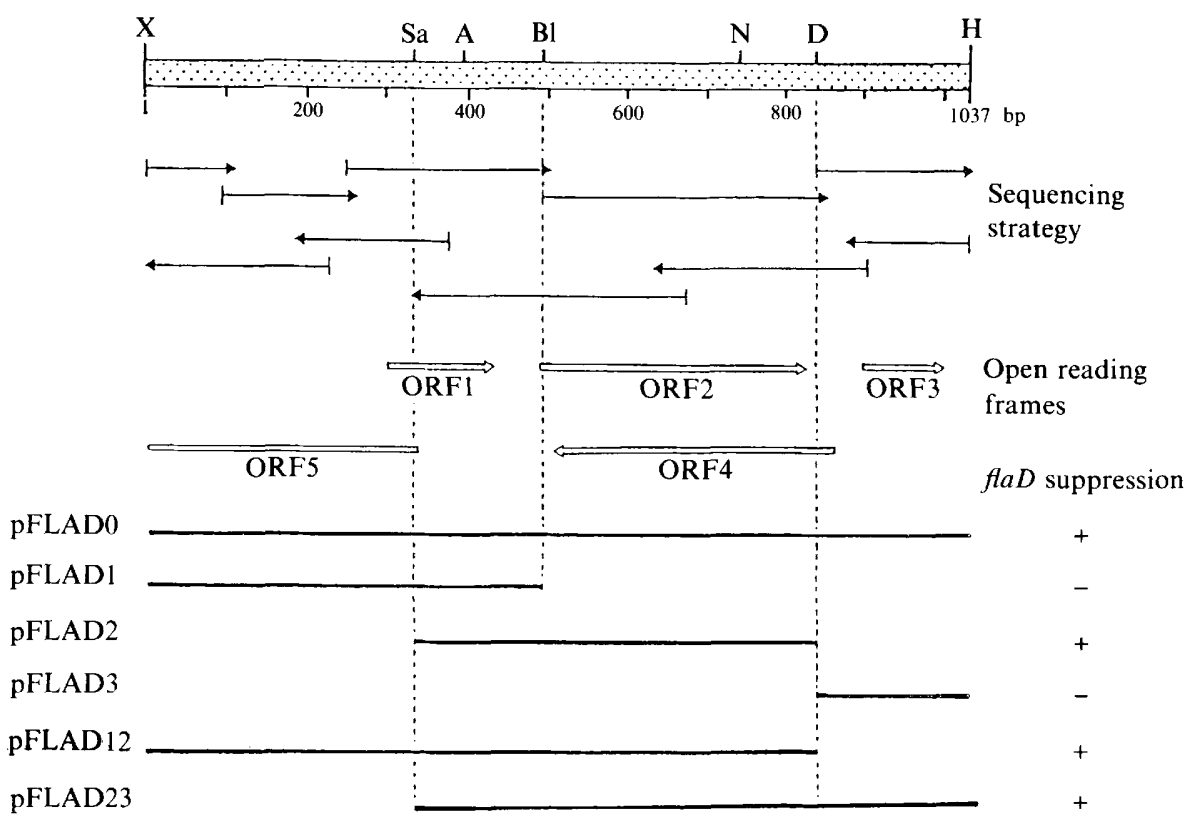

Fig. 1. Sequencing strategy for the cloned $1.0 \mathrm{~kb} \mathrm{~B}$. subtilis DNA insert in pFLAD, open reading frames and flaD suppression. Protoplasts of $B$. subtilis AC333 ( $\mathrm{faD} 2$ ) were transformed with various plasmids and flaD suppression was measured as to cell shape, motility and autolytic activity: + , rod and motile cells, and a wild-type level of autolytic activity; - , filamentous and non-motile, and a decreased level of autolytic activity. A, AvaI; Bl, BalI; D, DdeI; N, NruI; Sa, Sau3AI; H, HindIII; X, XbaI. Open arrows indicate the direction of transcription.

motif. It was therefore of interest to determine whether this motif is conserved in a homologous protein from a related organism. Gaur et al. (1986) reported that a strain carrying a disruption in the ORF1 (D-ORF1) of $B$. subtilis displayed an unusual aggregation of cells in the form of long chains, together with poor competence and an increase in protease activity, characteristics similar to those strains with a disruption in $\sin (f a D)$. Since longchain cells often show decreased autolytic activity (Ayusawa et al., 1975; Akamatsu \& Sekiguchi, 1987b; Chatterjee et al., 1976), it was thought that the D-ORF1 product might regulate expression of autolysin(s). This prompted us to clone $f a D$ and D-ORF1 homologues of $B$. licheniformis and to compare their amino acid sequences with those of $f a D$ and D-ORF1.

Cloning of a B. licheniformis homologue of the flaD gene of $B$. subtilis

We ligated HindIII-digested chromosomal DNA of $B$. licheniformis to the dephosphorylated HindIII site of pUC19, and the mixture was used to transform $E$. coli JM109, selecting ampicillin-resistant colonies. Three plates, each with about 500 colonies, were subjected to colony hybridization with pBRG1 as a probe. A hybridization-positive clone, LLYT-1, containing a $5.3 \mathrm{~kb}$ plasmid (pLLYT1) was selected. pLLYT1 contained two HindIII inserts $(2.4 \mathrm{~kb}$ and $0.3 \mathrm{~kb})$, as shown in Fig. 2. A $2.6 \mathrm{~kb}$ PstI fragment of pLLYT1 was subcloned into the Pst I site of pAC3; the resultant plasmids, pLLA and $\mathrm{pLLB}$, had the $B$. licheniformis DNA fragments inserted in opposite directions (Fig. 2).

Transformation of $B$. subtilis AG5 ( $f a D)$ with pLLA or pLLB resulted in suppression of the $\mathrm{FlaD}^{-}$phenotype (Fig. 3). A $1.5 \mathrm{~kb}$ EcoRI fragment of pLLYT1 was subcloned into the EcoRI site of pAC3 and the resultant plasmid, pEE, also suppressed the $\mathrm{FlaD}^{-}$phenotype (Fig. 3). The $1.5 \mathrm{~kb}$ inserted fragment was then cut with $X b a \mathrm{I}$ into two fragments $(0.9 \mathrm{~kb}$ and $0.6 \mathrm{~kb})$, which were subcloned separately into the $X b a \mathrm{I}$ and EcoRI sites of pUC19 (Fig. 2). The resultant plasmids (pXE and pXHE) did not contain the ori locus of $B$. subtilis. Thus the inserted fragments were subcloned into the Pst I and EcoRI sites of pAC3 (Fig. 2). These fragments had lost the ability to suppress FlaD- (Fig. 3), indicating that the $B$. licheniformis homologue ( $f a L)$ of $f a D$ is located around the $X b a I$ site.

Nucleotide sequence of the B. licheniformis homologue ( flaL) of the flaD locus

The sequencing strategy is outlined in Fig. 3 and the nucleotide sequence of $f a L$ region is shown in Fig. 4 . The sizes of the predicted polypeptide products of ORF1 (L-ORF1), ORF2 ( $f a L$ ) and ORF3 of B. licheniformis are 58, 111 and 77 amino acids, corresponding to molecular 


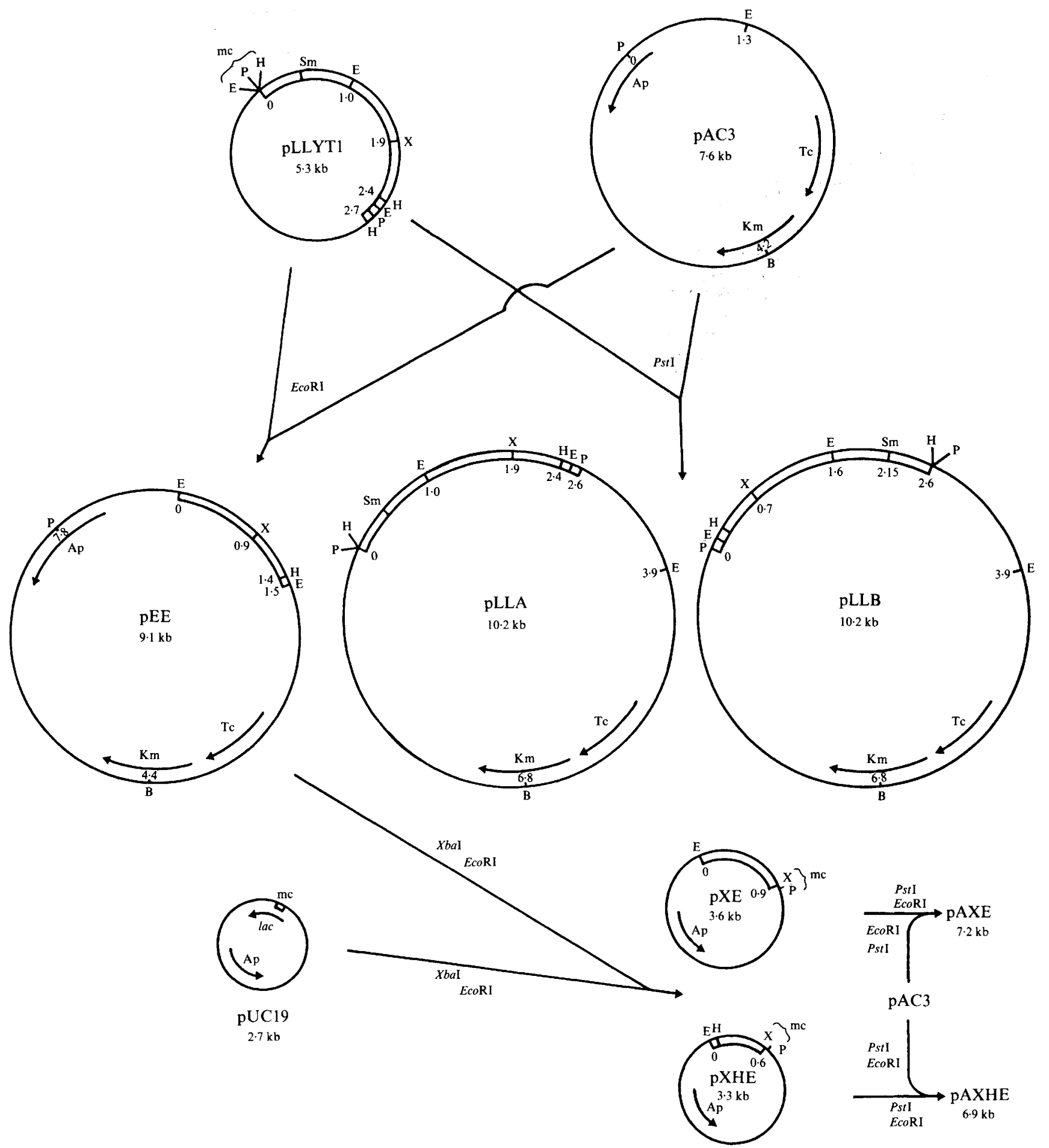

Fig. 2. Construction of plasmids. Blocks indicate the DNA from the B. licheniformis chromosome. Only relevant restriction endonuclease sites are indicated. The numbers around the plasmid circles indicate the distance in $\mathrm{kb}$ from the basal point. mc, multiple cloning site region; Ap, ampicillin resistance; Tc, tetracycline resistance; $\mathrm{Km}$, kanamycin resistance. B, BamHI; E, EcoRI; H, HindIII; P, PstI; Sm, SmaI; X, XbaI. 


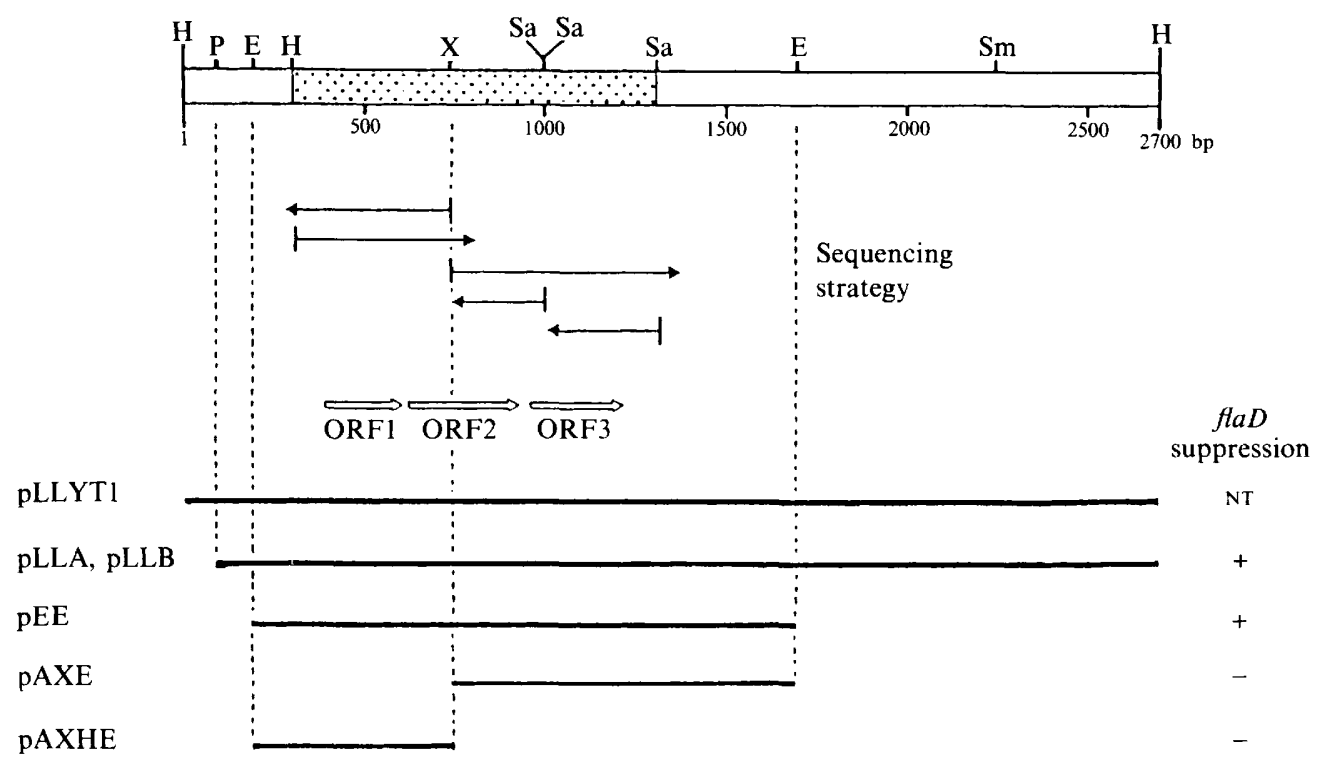

Fig. 3. Sequencing strategy for the cloned $0.9 \mathrm{~kb}$ B. licheniformis DNA insert in pLLYT1 and faD suppression by various plasmids. Protoplasts of $B$. subtilis AG5 ( $f a D)$ were used as recipient and flaD suppression was measured as described in Fig. 1. The abbreviations are given in the legends to Figs 1 and 2, except for NT (not tested). Sau3AI (Sa) sites were determined only for the dotted area.

masses of 6686,12946 and $9423 \mathrm{Da}$, respectively; those of D-ORF1, flaD and ORF3 of B. subtilis are 57, 111 and 35 amino acids, corresponding to molecular masses of 6593,12972 and $4224 \mathrm{Da}$, respectively. The $X b a \mathrm{I}$ site was found to be in $f l a L$, whose nucleotide sequence was $89 \%$ homologous to that of $f a D$. The nucleotide sequence of L-ORF1 was $58 \%$ homologous to that of D-ORF1. However, no homology was found between the ORF3s of the two species. Two presumptive ribosome-binding sites (SD1 and SD2) were found (Fig. 4), SD2 of $f a L$ being completely identical to that of $f a D$. ORF3 of $B$. licheniformis contained no recognizable ribosome-binding site (Fig. 4). The relatively uncommon start codon, UUG, found in $f a D$ was also observed in $f l a L$.

Gaur et al. (1988) reported that the sin gene is transcribed from a $\sigma^{\mathrm{A}}$-dependent promoter (P3) upstream of $f a D$ and also from the late-transcriptional promoters (P1 and P2) upstream of D-ORF1 as polycistronic transcripts. The -10 sequence of $\mathrm{P} 3$ (TATAAT; consensus sequence, TATAAT) was completely conserved in the $B$. licheniformis sequence (278283 from the HindIII site in Fig. 4), but the -35 sequence was rather different from the consensus sequence [CCGTAA for $B$. subtilis ; CAATAA (255-260) for $B$. licheniformis; consensus sequence, TTGACA]. The P2 promoter sequence of $B$. subtilis was not conserved in the $B$. licheniformis sequence. One of the two terminators of the $f l a D$ and D-ORF1-flaD transcripts was found downstream of $f l a L$ in B. licheniformis. A short inverted repeat was observed in the upstream regions of $f a L$ and $f a D$.
Strong homology of the amino acid sequences of $f a L$ and $f a D$ was observed (93\% homologous), all the different amino acid residues (eight amino acids) being located in the C-terminal half of the sequence, with four close to the C-terminus itself (Fig. 5). The difference between the nucleotide sequences of $f a L$ and $f a D$ was mainly at the third position of the codons ( 20 of the total 36 changes), and to lesser extents at the first, second and more than two positions ( 7,0 and 4 , respectively). These synonymous changes suggest that the amino acids are essential for function of $\mathrm{Sin} / \mathrm{FlaD}$. It was recently reported that the Sin protein is a DNA-binding protein (Gaur et al., 1989). The region ( $\mathrm{L}_{17}$ SELAEKAGVAKSYLSSIER $_{36}$ ), assumed to be a DNA-binding domain (Gaur et al., 1986), was completely conserved in $f a L$ (Fig. 5).

Comparison of the derived amino acid sequences of $L$ ORF1 and D-ORF1 showed the former to be one amino acid longer than the latter. The homology values $(50 \%$ for identical amino acids and $64 \%$ for conservative substitutions) were not as high as those for flaL and $f a D$ (Figs 5 and 6). The hydrophilicity profiles of their Nterminal and central regions were considerably different (Fig. 6). These results suggest that only a limited region of the amino acid sequence is required for its activity.

The sac $Q$ gene, which is pleiotropic, encodes a 46 amino acid polypeptide (Yang et al., 1986). The $\operatorname{sac} Q(\mathrm{Hy})$ mutation increases the activities of levansucrase, neutral protease, alkaline protease, $\alpha$-amylase, xylanase, intracellular serine protease and $\beta$-glucanase(s) (Henner et al., 1988). Henner et al. (1988) 
HindIII

AAGCTTGGTAAAGTGTTGAGTCTCGGGGTTTATCTTTGTTTATCACAACACGGTTGTCTG 60

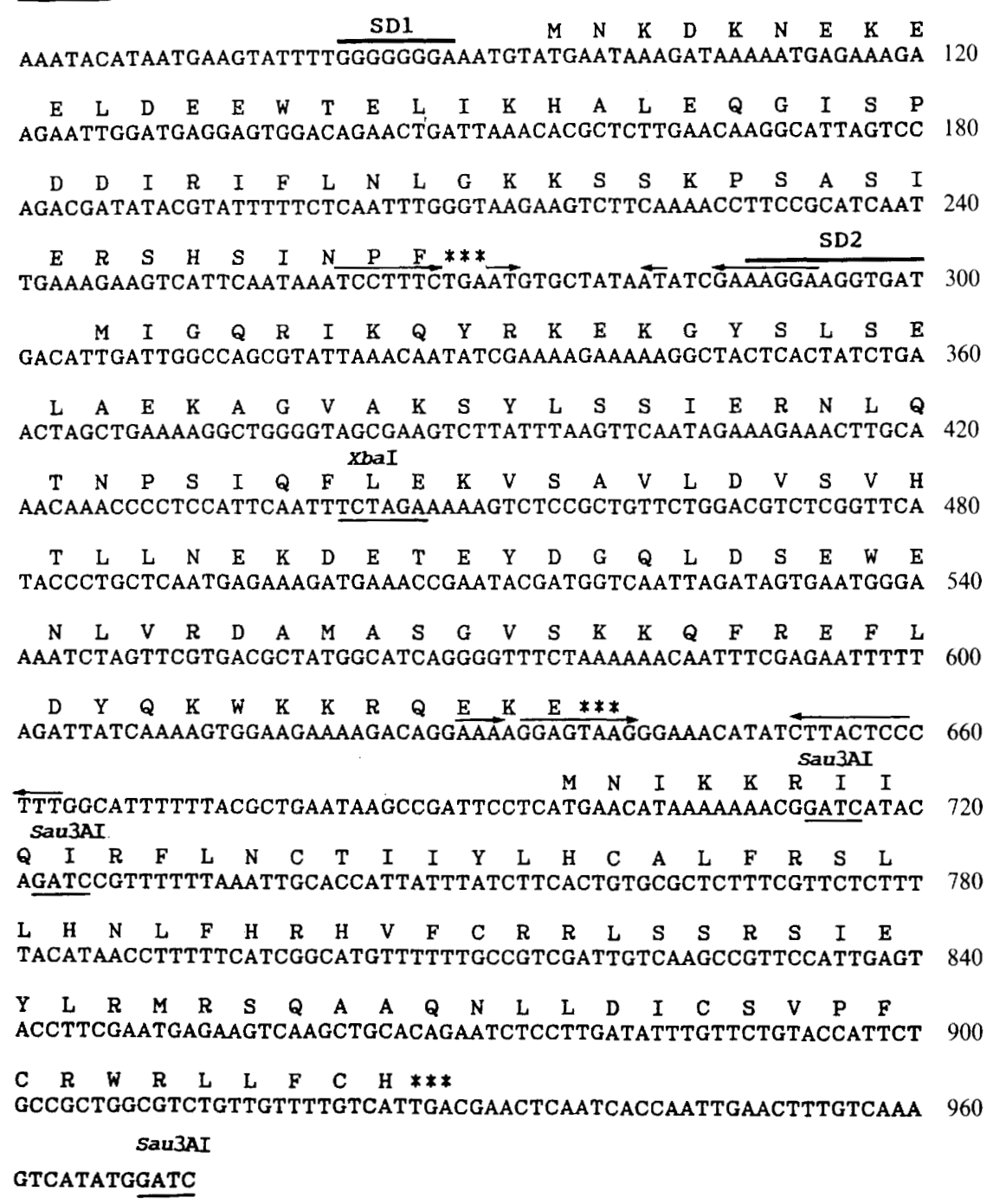

Fig. 4. Nucleotide sequence of the $0.95 \mathrm{~kb}$ HindIII-Sau3AI fragment in pLLYT1. The deduced amino acid sequence is given above the nucleotide sequence. Putative Shine-Dalgarno (SD) and inverted repeat (arrows) sequences are also indicated above the nucleotide sequence. ${ }^{* * *}$ corresponds to a stop codon.

suggested some similarity between the $s a c Q$ protein and the D-ORF1 gene product. In the specified region (42 amino acid residues), there were 11 identical residues and nine conservative substitutions. However, in the case of sac $Q$ and L-ORF1, only six residues were identical and there was only one conservative substitution. Therefore the sequence similarity of $\operatorname{sac} Q$ and D-ORF1 may have no meaning.
The widely used $\mathrm{FlaD}^{-}$mutants are $l y t-1$, lyt-2 and $r g n$ mutants. Complementation analysis of their mutations with a plasmid containing only the ORF2 ( $f l a D$ ) from $B$. subtilis $168 \mathrm{~W}$ indicated that their lesions are located in the $f a D$ gene itself. Recently, sequencing of the $f a D$ region, containing D-ORF1 and $f a D$, of two FlaD ${ }^{-}$ mutants, supported the above result (the sequence data will be published elsewhere). On the other hand, only

Fig. 6. Comparison of the deduced amino acid sequences, hydrophilicity and secondary structures of the L-ORF1 protein (a) and D-ORF1 protein $(b)$. Underlines indicate the different amino acids in the case of the best alignment of L-ORF1 and D-ORF1 (there is assumed to be a space after the 46 amino acids from the $\mathrm{N}$-terminus of D-ORF1). For the protein secondary structure and hydrophilicity, see the legend to Fig. 5. 

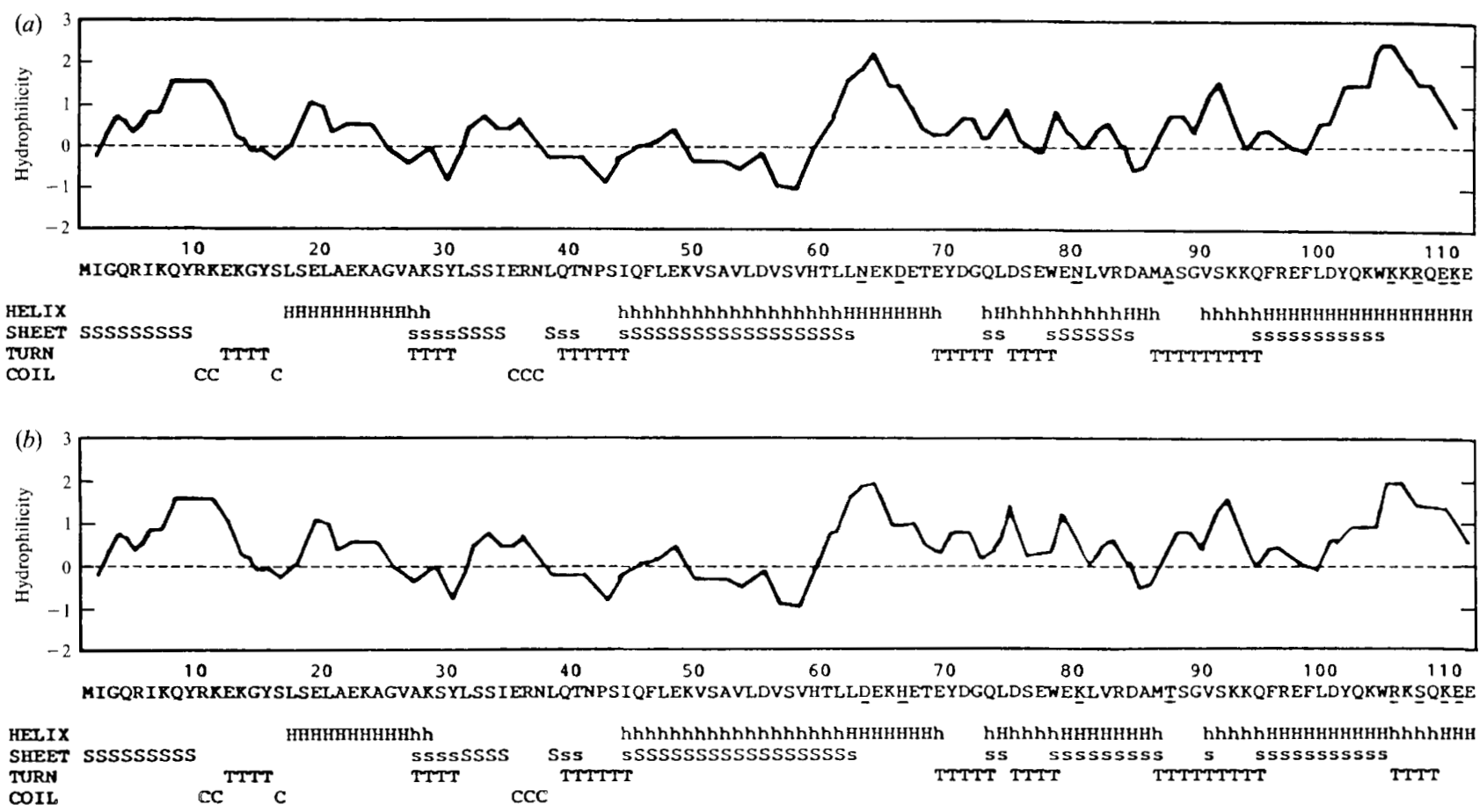

Fig. 5. Comparison of the deduced amino acid sequences, hydrophilicity and secondary structures of the $f l a L$ protein $(a)$ and $f a D(s i n)$ protein $(b)$. Lines below the amino acid sequences indicate the amino acids that differ between the two sequences. The DNASIS program (Hitachi-SK) was used, the analysis being based on the papers of Kyte \& Doolittle (1982), and Rose \& Roy (1980) for the hydrophilicity profile, and of Chou \& Fasman (1978) and Rose (1978) for the protein secondary structure. Hydrophilicity is presented as the running average for six amino acids.
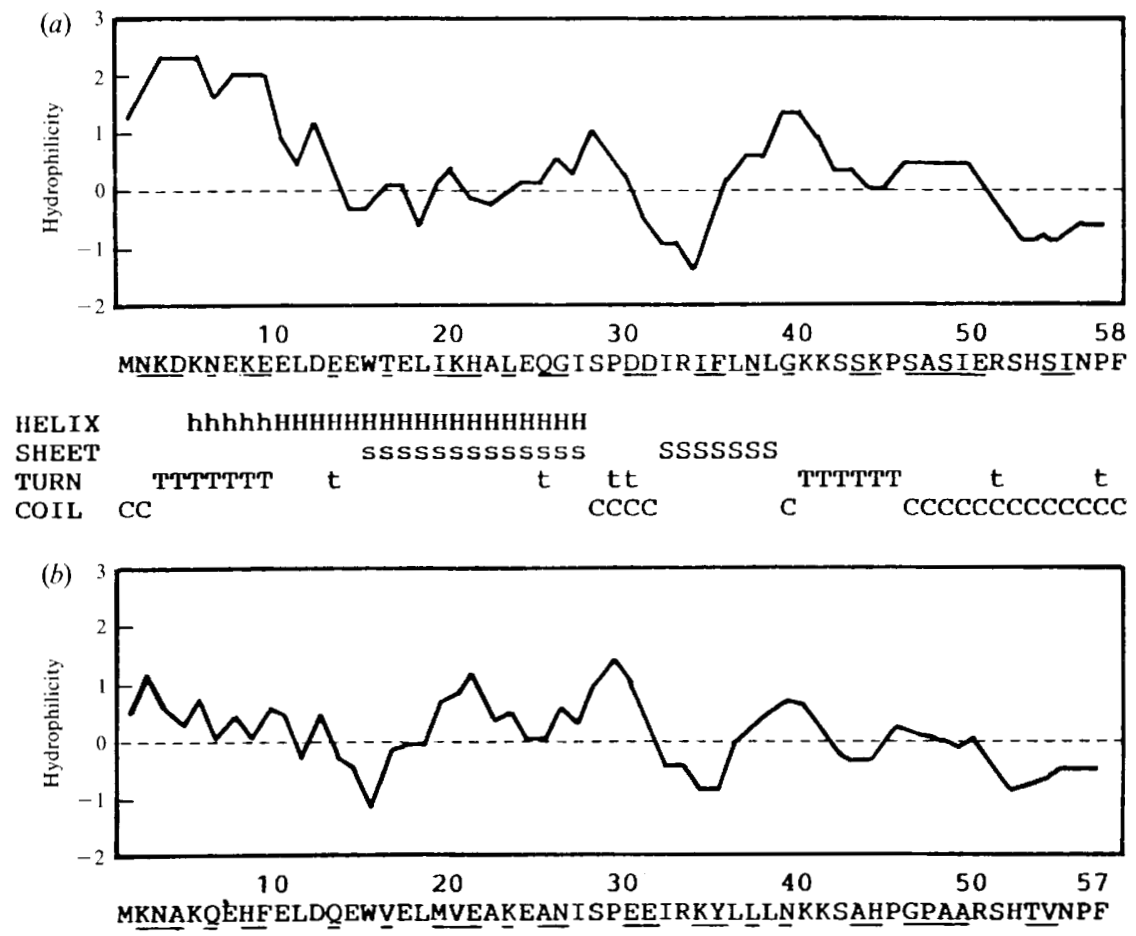

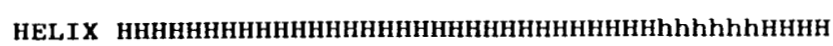
SHEET
TURN
$t \quad t \quad s s s$
sssisss
tt
SSSSSSs
tt $\frac{t}{\operatorname{ccccccccccc}}$
SSSS
COIL 
limited research has been done on a strain carrying a disruption in D-ORF1, and the role of D-ORF1 is still obscure. Thus our research is directed toward the isolation of D-ORF1 mutants and the characterization of D-ORF1.

The identification of the $f l a D$ protein as the sin protein should help to clarify the pleiotropic effects of the $f a D$ mutation. Some properties believed to be the effects of autolysin(s) may in fact not be related to the activity of autolysin(s).

\section{References}

Akamatsu, T. \& Sekiguchi, J. (1983). Properties of regeneration mutants of Bacillus subtilis. FEMS Microbiology Letters 20, 425-428.

Akamatsu, T. \& Sekiguchi, J. (1984). An improved method of protoplast regeneration for Bacillus species and its application to protoplast fusion and transformation. Agricultural and Biological Chemistry 48, 651-655.

AKAMATSU, T. \& SEKIGUCHI, J. (1987a). Genetic mapping by means of protoplast fusion in Bacillus subtilis. Molecular and General Genetics 208, 254-262.

Axamatsu, T. \& Sekiguchi, J. (1987b). Genetic mapping and properties of filamentous mutations in Bacillus subtilis. Agricultural and Biological Chemistry 51, 2901-2909.

Ayusawa, D., Yoneda, Y., Yamane, K. \& Maruo, B. (1975). Pleiotropic phenomena in autolytic enzyme(s) content, flagellation, and simultaneous hyperproduction of extracellular $\alpha$-amylase and protease in a Bacillus subtilis mutant. Journal of Bacteriology 124, 459-469.

Chatterjee, A. N., Wong, W., Young, F. E. \& Gilpin, R. W. (1976). Isolation and characterization of a mutant of Staphylococcus aureus deficient in autolytic activity. Journal of Bacteriology 125, 961-967.

ChOU, P. Y. \& FASMAN, G. D. (1978). Empirical predictions of protein conformation. Annual Review of Biochemistry 47, 251-276.

FEIN, J. E. (1979). Possible involvement of bacterial autolytic enzymes in flagellar morphogenesis. Journal of Bacteriology 137, 933-946.
Fein, J. E. \& Rogers, H. J. (1976). Autolytic enzyme-deficient mutants of Bacillus subtilis 168, Journal of Bacteriology 127, 1427-1442.

Gaur, N. K., DubnaU, E. \& SMith, I. (1986). Characterization of a cloned Bacillus subtilis gene that inhibits sporulation in multiple copies. Journal of Bacteriology 168, 860-869.

GaUR, N. K., Cabane, K. \& Smith, I. (1988). Structure and expression of the Bacillus subtilis sin operon. Journal of Bacteriology 170, 1046-1053.

Gaur, N., Mandic-Mulec, I. \& SMith, I. (1989). The late growth regulatory gene, sin, encodes a DNA binding protein. In Abstracts of the 5th International Conference on Bacilli, Asilomar, abstract no. G-1.

Henner, D. J., Ferrari, E., Perego, M. \& Hoch, J. A. (1988). Upstream activating sequences in Bacillus subtilis. In Genetics and Biotechnology of Bacilli, vol. 2, pp. 3-9. Edited by A. T. Ganesan \& J. A. Hoch. New York: Academic Press.

KYTE, J. \& DoolitTle, R. F. (1982). A simple method for displaying the hydropathic character of a protein. Journal of Molecular Biology 157, 105-132.

Maniatis, T., Fritsch, E. F. \& Sambrook, J. (1982). Molecular Cloning, a Laboratory Manual. Cold Spring Harbor, NY: Cold Spring Harbor Laboratory.

Mendelson, N. H. (1982). Bacterial growth and division: genes, structures, forces, and clocks. Microbiological Reviews 46, 341-375.

Moriyama, H., Akamatsu, T. \& Sekiguchi, J. (1988). Stable shuttle plasmid, pAC3, among Bacillus subtilis, B. megaterium and Escherichia coli. Nucleic Acids Research 16, 8732.

Pooley, H. \& Karamata, D. (1984). Genetic analysis of autolysindeficient and flagellaless mutants of Bacillus subtilis. Journal of Bacteriology 160, 1123-1129.

Rose, G. D. (1978). Prediction of chain turns in globular proteins on a hydrophobic basis. Nature, London 272, 586-590.

ROSE, G. D. \& Roy, S. (1980). Hydrophobic basis of packing in globular proteins. Proceedings of the National Academy of Sciences of the United States of America 77, 4643-4647.

Sekiguchi, J., Ezaki, B., Kodama, K. \& Akamatsu, T. (1988). Molecular cloning of a gene affecting the autolysin level and flagellation in Bacillus subtilis. Journal of General Microbiology 134, 1611-1621.

Yang, M., Ferrari, E., Chen, E. \& Henner, D. J. (1986) Identification of the pleiotropic sacQ gene of Bacillus. Journal of Bacteriology 166, 113-119.

Yanisch-Perron, C., Vieira, J. \& Messing, J. (1985). Improved M13 phage cloning vectors and host strains: nucleotide sequences of the M13mp18 and pUC19 vectors. Gene 33, 103-119. 